\title{
The Formalization of Critical Discussion
}

\author{
Erik C. W. Krabbe ${ }^{1}$
}

Published online: 25 March 2016

(C) The Author(s) 2016. This article is published with open access at Springerlink.com

\begin{abstract}
This paper makes an independent start with formalizing the rules for the argumentation stage of critical discussions (van Eemeren and Grootendorst $A$ systematic theory of argumentation: The pragma-dialectical approach, Cambridge University Press, Cambridge, 2004, Ch. 6). It does not deal with the well-known code of conduct consisting of ten rules (the "ten commandments") but with the system consisting of fifteen (or seventeen) rules on which the code of conduct is based. The rules of this system are scrutinized and problems they raise are discussed. Then a formal dialectical system is defined that reflects most of the contents of these rules. The aim is to elucidate the way the rules work and to show how a formal approach can be useful to achieve this. It is also shown how the present method can be used to study the nature of circular argumentation. While, generally, the formalization follows closely the original rules for the argumentation stage of critical discussions, there will also be proposed some modifications of the original protocol.
\end{abstract}

Keywords Argumentation stage - Conclusive attacks/defenses - Critical discussion · Formalization · Pragma-dialectics · Successful defenses

\section{Introduction}

Arend Heyting, the mathematician who formalized Brouwer's intuitionistic logic, once had a conversation with his student and colleague the philosopher and logician Else Barth, who is well known for her considerable contributions to the development of argumentation theory. "Why don't you philosophers formalize

Erik C. W. Krabbe

e.c.w.krabbe@rug.nl

1 Faculty of Philosophy, University of Groningen, Oude Boteringestraat 52, 9712 GL Groningen, The Netherlands 
philosophy?" Heyting asked. ${ }^{1}$ Well, why not? It may be a lot of work, but why not make a start? A similar question might be asked about the views of pragmadialectics: Why shouldn't we try to formalize those? Again, that will be quite some job. Yet, in this paper I want to make a start. ${ }^{2}$

Pragma-dialectics comprises views on philosophical, theoretical, analytical, empirical, and practical matters (van Eemeren and Grootendorst 2004, Chapter 2). Not all that is said in these branches lends itself to formalization. The part of pragma-dialectics I would like to formalize is its theoretical model for conducting a critical discussion. Perhaps that is the only part of pragma-dialectics that offers suitable material for formalization. But moreover, I want to focus on rules of procedure, in particular those rules that concern the argumentation stage of the discussion, namely rules 6 through 13 (van Eemeren and Grootendorst 2004, pp. 144-154), which are cited in the appendix. As I mention these numbers, it may occur to you that I cannot be referring to the well-known system of ten pragmadialectical rules, also known as the "ten commandments" (van Eemeren and Grootendorst 1992, 2004), which together constitute a code of conduct. Indeed, I am referring to the also well-known (but perhaps not equally well-known) system of seventeen (van Eemeren and Grootendorst 1984) or fifteen (van Eemeren and Grootendorst 2004) rules. This latter system provides theoretical underpinnings for the former. The formalization departs from the latest published version, the one with fifteen rules (van Eemeren and Grootendorst 2004), to which I shall refer as "the original version" (namely, the version to be formalized, not the historically first version).

What do I mean by "formalizing" those rules? Just that I want to define a formal dialectical system for the argumentation stage of critical discussion that concurs with the intentions reflected in those rules. That system is to be formal in various respects (cf. van Eemeren et al. 2014, p. 303): (1) meticulously formal in a "regulative sense": it must be unambiguously determined how discussions begin and how they end, which roles there are, which moves can legitimately follow upon a certain kind of move, and what the consequences of each move are, in such a way that it becomes a completely mechanical affair to check whether a dialogue instances correct performance or not (the system of fifteen rules is itself formal in a regulative sense, but not to such an extent that such mechanical decisions are possible); (2) formal in a "linguistic sense": the language used in the discussion must be a formal language, as in logical systems (this does not imply that the rules defining the formal system must themselves be formal in this sense); (3) formal in an "a priori sense": The formal system's definition is, just as the system of fifteen rules, to be a stipulative construction and not a stylized rendering of observed

\footnotetext{
1 According to what I remember to have heard from Else Barth.

2 This is not to claim that this has been the first, or even the only, start. About the time I first took up the subject (2011) and later, there were also other attempts to formalize parts or aspects of the pragmadialectical model of critical discussion (Visser et al. 2011; Visser 2013, 2015a, b; Secades 2015). The present work is, in its objectives as well as in its formalization technique, closely related to, though independent of, Visser's (2015a, b) approach but offers different solutions for various problems; it is somewhat further removed from the other approaches.
} 
behavior in actual discussions. Thus the dialectical system I aspire to construct is formal in the same ways that systems of formal logic are formal.

What do I hope to achieve by formulating such a formal dialectical system? The primary aim is to gain insight into the way the original rules for critical discussion function at the argumentation stage. Specifying the details of a formalization forces the researcher to scrutinize the procedures such as they are prescribed in the original informal rules. It may then appear that these informal rules are still at certain points ambiguous or unclear. It may also be discovered that rules that separately appear to be completely reasonable lead together to incongruities. The attempt at formalization here presented will therefore occasion proposals for modifying the original protocol.

Before presenting, in Sect. 3, a definition of a formalized system for the argumentation stage of critical discussion, I shall first discuss a number of problems I met on the way leading to that result (Sect. 2). After having defined a formal dialectical system, I show how formalization can be applied in the study of circular argumentation (Sect. 4) and add some concluding observations (Sect. 5).

\section{Problems and Considerations}

Van Eemeren and Grootendorst (2004, p. 143) start their discussion of the rules for the argumentation stage of critical discussion with a list of speech acts that may legitimately be performed at this stage. Rule 6 determines the rights to attack (or challenge) and to defend of the two parties (the Antagonist and the Protagonist). Rules 7, 8, and 9 define when an attack or a defense counts as successful and when a standpoint has been conclusively attacked or defended. These concepts are crucial for determining — at the concluding stage — the result of the argumentation stage but they are also used in the description of the argumentation stage itself. Rules 10 and 11 stipulate that rights to attack and to defend are in principle retained throughout the entire discussion. Rule 12 grants the Protagonist a right to retract arguments he has put forward. Rule 13 prescribes an orderly conduct of the discussion by outlawing repetitions and letting the parties move alternately.

\subsection{The Speech Acts and Discussion Moves of the Argumentation Stage}

At first, Van Eemeren and Grootendorst (2004, p. 143) restrict the types of speech act of the argumentation stage of critical discussion to assertives, commissives, and directives. More specifically they admit the following kinds of speech act: (1) argumentation (a complex speech act in defense of a standpoint); (2) acceptance (a commissive that is not a part of an attack or a defense); (3) negation of acceptance (a commissive that is part of an attack); (4) request (a directive that also seems to be part of an attack). ${ }^{3}$

This list of speech acts will underlie the choice of locution rules for the formalization. However, the speech act of acceptance can be omitted from the

\footnotetext{
${ }^{3}$ Here I omit the (requests for) usage declaratives, which may occur at any stage of a critical discussion.
} 
formalization because we shall assume that any unattacked part of an argument counts as having been accepted for the time being. As moves in the formalized system we want to construct we then just have: (1) attacks or challenges (which may be analyzed as being composed of two speech acts: negation of acceptance and request, namely a request to provide a defense) and (2) defenses such as providing argumentation.

The only defense move mentioned thus far is the complex speech act argumentation. But it appears that, according to the original version, the Protagonist may avail himself also of other means of defense, namely the joint execution of certain tests. By the intersubjective identification procedure (IIP) discussants check whether a proposition can be identified with one of those that were-at the opening stage-accepted by both (pp. 145-147) ${ }^{4}$; by other tests, ${ }^{5}$ which we here for convenience merge into one test to be called the intersubjective linking procedure (ILP), they check whether an argument has sufficient force of justification (pp. 148-150). ${ }^{6}$ The Protagonist may appeal to these tests in order to defend an attacked premise (IIP) or an attacked link between premises and standpoint in an argument (ILP). It seems reasonable to count the appeal to a test at the argumentation stage as another kind of defense move, besides argumentation. ${ }^{7}$ On the level of speech acts such a move would, so I suggest, consist of a directive: demanding, namely demanding that a certain test will be executed (refusals are not permitted). This way to defend would then have to be included in Rule 6a (p. 144) of the original version. In the formalization we use corresponding locutions ("Test").

\subsection{The Focus of an Attack}

What can be the focus of an attack (or challenge) by the Antagonist? According to Rule $6 \mathrm{~b}$ (p. 144), an attack must either focus on the propositional content of an argument that has been presented in defense of a standpoint (i.e. on the propositional content of its premises) or on its force of justification. A direct attack on the initial standpoint is not included. It is left out because it is supposed to have already occurred at the opening stage. For there we find a "challenge" in response to the standpoint that was put forward at the confrontation stage (see p. 68, pp. 137ff, and Rule 4, p. 142). When constructing a simple formalized version of the argumentation stage, one may indeed let the discussion start with a given standpoint and a given first attack on the standpoint (In Table 1, below, the first two moves would then be replaced by a text citing the fact that there is a standpoint $\mathrm{B}$ that has been

\footnotetext{
${ }^{4}$ Van Eemeren and Grootendorst first describe this procedure as checking whether a proposition occurs on a list of agreed proposition but later allow also for testing the acceptability of a proposition by various methods, provided the latter are agreed on by both parties (2004, pp. 145-147).

${ }^{5}$ The intersubjective inference procedure, the intersubjective explicitization procedure, and the intersubjective testing procedure.

${ }^{6}$ In the case of a negative standpoint, one has to check the force of refutation instead of the force of justification. However, I shall not deal with negative standpoints.

${ }^{7}$ Such a defense move is, in the original system, excluded by Rule 6 (see esp. Rule 6c) but van Eemeren and Grootendorst also seem to see an appeal to a test as a method of defense where they speak of "This method of defense by the protagonist..." (2004, p. 146).
} 
challenged). However, with a view to the future formalization of more complex variants of critical discussion (incorporating debate on a plurality of formulations of the standpoint and admitting different kinds of attack on a standpoint) it is more practical to construct a formalized argumentation stage that includes (or repeats) the move in which the Protagonist puts forward his standpoint as well as the move in which the Antagonist attacks it (as seen in Table 1). In that way, new possibilities for the argumentation stage (such as debates on ambiguity) can easily be formalized by constructing an extension of the simple formalization we now seek to achieve.

Another point of difference between the formalized version of critical discussion and the original version is that the formalized version will for convenience admit as a borderline case the defense of the initial standpoint by an appeal to the IIP. Thus we get rid of what otherwise would have been an exception to the rule that, for each proposition brought forward by the Protagonist and attacked by the Antagonist, the former may have recourse to the IIP. When such an appeal is successful, the discussion will of course soon be over. In fact, we then have an argumentation stage without argumentation.

A more important difference lies in the distinction between different kinds of attack on the propositional content of an argument that will figure in the formalized version, but has no place in the original version. In the original version the focus of such attacks is the propositional content as a whole. But suppose this content consist of a number of premises (propositions) and that some of these may be defended by an appeal to the IIP, but others only by means of argumentation. If the Antagonist attacks the propositional content as a whole, what should the Protagonist do? He will have to choose for further argumentation to stand a chance of winning. His additional argument must then, in order to succeed, defend the whole of the propositional content of the earlier argument, i.e. the conjunction of all premises of the latter, including those that might more easily have been defended by an appeal to the IIP. Otherwise the force of justification of the added argument would fall short.

Suppose, for instance, that the standpoint (1) "We are our brains" is defended by means of an argument with the following premises: (1.1a) "Professor S claims that we are our brains"; (1.1b) "Professor S is an expert in the field of neurobiology"; (1.1c) "The statement that we are our brains belongs to the field of neurobiology." Suppose that the Antagonist doubts only (1.1b) but attacks the (whole of the) propositional content of this argument and that the Protagonist can easily defend (1.1a) and (1.1c) with an appeal to the IIP, but can defend (1.1b) only by means of further argumentation, namely: (1.1b.1) "Professor S has published more than 400 papers in SCI journals within the field of neurobiology." Since (1.1b.1) falls short as a defense of (1.1a) and (1.1c), while these are part and parcel of the propositional content that was attacked, the Protagonist must include these latter propositions as premises in his additional argument. This argument will therefore have the premises (1.1a), (1.1c) and (1.1b.1) in order to be able to defend the conjunction of (1.1a), (1.1b), and (1.1c).

Granted that it is not impossible to regiment the discussion in this way, it would be disastrous for the role of the Antagonist in critical discussion. The Antagonist has a directive role, according to which she should prompt the Protagonist to defend just those propositions that are not immediately acceptable to her (in the example only 
(1.1b)). This role would now get a very narrow scope indeed. Therefore a choice has been made to stipulate in the formalized version that attacks of the Antagonist that concern the propositional content of an argument will always focus on some particular premise of that argument.

\subsection{Successful and Conclusive Attacks and Defenses}

About the notions "successful defense," "conclusive defense," "successful attack," and "conclusive attack," which are defined in Rules 7, 8 en 9 (van Eemeren and Grootendorst 2004. pp. 147, 150-151), I wrote before in (Krabbe 2007). There I argued that these rules taken together do indeed define these notions (by means of a complex inductive definition) and also proposed some slightly modified definitions, the gist of which I shall now briefly explain. ${ }^{8}$

During the course of the discussion, the Protagonist constructs by means of the separate arguments that he puts forward (which I shall call elementary arguments) an argument with an ever more complex argumentation structure. An elementary argument can be rendered as $A_{1}, \ldots, A_{n} / S$, where $A_{1}, \ldots, A_{n}$ stand for those propositions that figure as premises and $S$ stands for the proposition that is being defended as (sub)standpoint. All these propositions are elements of the argument that is being constructed. The link between $A_{1}, \ldots, A_{n}$ and $S$ (the force of justification of the argument) counts also as an element (the linking element). Hence the elements are precisely those objects that can be the focus of an attack by the Antagonist. An element that has been tested (by the IIP or the ILP) with a (for the Protagonist) positive result, I shall call fixed. A simple inductive definition ${ }^{9}$ of the predicate successfully defended (as applied to elements of the argumentation structure constructed in the discussion up to a certain moment), can now be formulated as follows:

(a) (Basic clause) Each fixed element counts as successfully defended.

(b) (Inductive clause) Each element that has been defended by means of an argument in which it holds for each premise as well as for the link that it either (i) has not been attacked at all (whereas the Antagonist has had sufficient opportunity to do so) or (ii) has been successfully defended, counts as successfully defended.

(c) (Extremal clause) No element counts as successfully defended, unless on the basis of clauses a) and b) (paraphrasing Krabbe 2007, p. 7).

An initial standpoint or sub-standpoint of which the propositional content is an element that has been successfully defended counts as conclusively defended.

The question that remains to be settled is: What does "having had sufficient opportunity to attack an element" exactly mean? The answer depends on the totality

\footnotetext{
8 The original rules (without modifications) are found in the "Appendix".

9 For the notion of an "inductive definition," see Kleene (1967 p. 20). It is not unusual to call such definitions "recursive," but I would prefer to reserve that term for similarly structured definitions that define a function over an inductively defined set of objects, such as the natural numbers (Kleene 1967. pp. 217, 258ff.).
} 
of rules of discussion because only taken together do the rules of discussion determine the possible courses of a discussion and thus which opportunities there were for putting forward a certain move. In any case, it will not always suffice that there has been a moment at which the Antagonist could have attacked the element, because at such a moment there might be other moves available for the Antagonist that are equally urgent, or even more urgent. Since at the end of the argumentation stage it must be clear whether or not the initial standpoint has been conclusively defended, one should take care, when formalizing critical discussion, that it will always be clear whether or not the Antagonist has had sufficient opportunity to attack elements.

\subsection{Retaining One's Rights to Attack or to Defend}

Rules 10 and 11 allow discussants, under conditions, to perform at a later point in the discussion certain moves that they earlier left undone (van Eemeren and Grootendorst 2004, pp. 151-152). In these rules, use is made of the notion of a "successful defense" discussed above. This notion is therefore seen to be of importance, not only for the concluding stage, but also for the argumentation stage. Of course the Antagonist must be enabled to attack both the propositional content and the force of justification of each argument. In the formalized version, this is mirrored by enabling her to attack (challenge) each element. Also the Protagonist must be enabled to defend himself against each attack (and, in the case of an attack on a proposition, to appeal to the IIP as well as to defend by means of argumentation). This aim can indeed be reached by means of such rules as Rule 10 and Rule 11, but also by allowing each participant to consecutively make a number of moves, in other words, by letting turns of participants consist of a series of moves. This is the way chosen for the formalized version.

\subsection{Retraction}

Rule 12 allows the Protagonist to retract arguments (van Eemeren and Grootendorst 2004, pp. 152-153). Retraction is not a defense move and allowing such a move to be performed at the argumentation stage of critical discussion may lead to complications, in particular if the participants are allowed only one move in each turn. Suppose the last attack before the retraction was focused on an element that was no part of the retracted argument. And suppose that the Antagonist, after the retraction, performs another attack. The result would be that the Protagonist has now at least two elements to defend. ${ }^{10}$ If only one move per turn is allowed, the

\footnotetext{
${ }^{10}$ Or three, if the retraction itself also leaves an element undefended. An example would be that the initial standpoint $\mathrm{S}$ is attacked and defended by $\mathrm{P}$, that $\mathrm{P}$ is attacked and defended by $\mathrm{Q}$, and that $\mathrm{Q}$ is attacked and defended by R. Next, the Antagonist attacks the link from $\mathrm{P}$ to S. Now the Protagonist retracts R. Suppose The Antagonist now attacks the link from Q to P. Then P has three attacked elements to defend: $\mathrm{Q}$, the link from $\mathrm{Q}$ to $\mathrm{P}$, and the link from $\mathrm{P}$ to $\mathrm{S}$.
} 
Protagonist can only defend one of them in one turn. Consequently, if there are no further retractions, there will be from now on at the start of each turn of the Antagonist at least one attacked and undefended element, and after the Antagonist's new attack again at least two attacked and undefended elements. If there are, at a certain point, no more elements for the Antagonist to attack (the Protagonist has made the last move, after which there happens to be no possible move for the Antagonist) the discussion will end with an attacked but undefended element. This would frustrate the Proponent's right of retaining rights to defend (Rule 11). In the formalized version this complication will not arise because there a series of moves is allowed in each turn, so that the Protagonist can catch up with the Antagonist. To keep this first attempt at formalizing part of critical discussion simple, I shall however omit moves of retraction.

\subsection{Orderly Conduct}

As an important part of their "regulations for the orderly conduct of a critical discussion" van Eemeren and Grootendorst propose Rule 13 (2004, pp. 153-154). This rule (a) outlaws repetition of a (complex) speech act, if this speech act plays the same role as before; (b) stipulates that the discussants "must in turn make a move of (complex) speech acts with a particular role in the discussion;" (c) outlaws that discussants "perform more than one move of (complex) speech acts at one time" (2004, p. 154).

For the interpretation of these rules, it matters a lot what is meant by a "move of (complex) speech acts." If this phrase refers to a speaker's turn, a move that may itself consist of a number of what we shall call elementary moves (such as attacks or defenses, which may indeed be analyzed in terms of (complex) speech acts) the formalized version will concur with Rules $13 \mathrm{~b}$ and 13c. But since "at one time" most likely must be interpreted as "in one turn," Rule 13c would then be trivial. If we interpret "move of (complex) speech acts" as "elementary move," we can see that above another choice has already been made: in the formalized version, discussants are allowed to put forward more than one attack or one defense. In this way, the formalized version guarantees in a simple way that everyone can make an optimal use of his or her rights.

Instead of the ban on repetitions of speech acts formulated in Rule 13a, but serving the same purpose, the formalized version will feature a ban on repeating elementary moves (locutions).

\subsection{Survey of Deviations}

Before describing the details of the formalization, I here present a survey of the points where this formalization deviates from the original version, which were discussed in this section: 
1. The original version starts from speech acts, the formalization from elementary moves (Sect. 2.1).

2. The formalization does not contain a locution corresponding to the speech act of acceptance (Sect. 2.1).

3. The formalization recognizes, besides argumentation, also the demand for the performance of a test as a way of defense for the Protagonist (Sect. 2.1).

4. The formalization incorporates (or repeats) positing the initial standpoint and challenging the initial standpoint as moves in the argumentation stage (Sect. 2.2).

5. The formalization permits a defense of the initial standpoint by means of demanding a test instead of argumentation (Sect. 2.2).

6. Attacks on the propositional content of argumentation as permitted in the original version are in the formalization replaced by attacks on separate premises (Sect. 2.2).

7. The definitions of "successfully defended" and "conclusively defended" of the original version are replaced by simpler definitions for the formalization (Sect. 2.3).

8. In the original version the players retain their rights of attack and defense throughout the discussion, whereas in the formalization such rights can only be used in the first turn after they were obtained (Sect. 2.4).

9. The original version allows only one "move of (complex) speech acts" in a turn, whereas the formalization has no such restriction with respect to elementary moves (Sect. 2.4).

10. The formalization does not allow retractions (Sect. 2.5).

11. The ban on repeating speech acts in the original system is replaced by a ban on repeating elementary moves (Sect. 2.6).

\section{The Formalization}

In this section, I shall define a formal dialectical system to be called " $\mathrm{CD}_{1}$ " (CD for Critical Discussion), where "formal" is to be understood as explained in the introduction. This system corresponds to the argumentation stage of the theoretical model for conducting critical discussion but includes the introduction of the initial standpoint and the initial challenge directed at this standpoint. There are two roles: the role of Protagonist (P) and the role of Antagonist (A). The player taking on the role of $\mathbf{P}$ takes the odd turns, the player taking on the role of $\mathbf{A}$ the even ones. To explain the system, I first describe the first five turns of any discussion following its rules.

At the start of the discussion (turn 1) $\mathbf{P}$ puts forward a standpoint, using the formal expression (or locution) devised for this purpose: "Standpoint $S$ ". $S$ will count as an element of the argument that $\mathbf{P}$ is going to construct.

In the next turn (turn 2), A challenges $\mathbf{P}$ to defend $S$, using the formal expression "Challenge $S$ ". ${ }^{11}$

11 Or "Attack S", if one doesn't mind the martial metaphor. 
In his second turn (turn 3), $\mathbf{P}$ is then to defend $S$. He can proceed in two ways: (1) $\mathbf{P}$ may appeal to the intersubjective identification procedure (or test) IIP to see whether $S$ is or should be a "shared premise," using the expression "Test ${ }_{\text {I }} S$ ". The test will then be performed. Tests are here represented by functions (I for the IIP and $\mathbf{L}$ for the ILP) with values 1 (for passing) and 0 (for failing). If the result is positive (notation: $\mathbf{I}(S)=1$ ), I shall say that $S$ has been fixed and that the defense has been successful; if the result is negative $(\mathbf{I}(S)=0)$, this way of defending the standpoint has failed, but the second way is still open. ${ }^{12}$ (2) $\mathbf{P}$ may also defend $S$ by putting forward an elementary argument with premises $P_{1}, \ldots, P_{n}$, using the formal expression: "Argument $P_{1}, \ldots, P_{n} / S$ ". Each of the premises $P_{1}, \ldots, P_{n}$ as well as the link between these premises and $S$ will be an element of the argumentation constructed by the Protagonist.

In her second turn (turn 4), A may challenge as many of the premises $P_{1}, \ldots, P_{n}$ as she likes and also challenge the link between these premises and $S$. For challenging premises, the formal expressions are of the form: "Challenge $P_{i}$ ", and for challenging the link of the form: "Challenge $P_{1}, \ldots, P_{n} / S$ ".

In his third turn (turn 5), $\mathbf{P}$ can try to defend himself against these challenges. For each premise $P_{i}, \mathbf{P}$ can proceed in either or both of the two ways that were also available for parrying the attack on the initial standpoint $S$ : (1) an appeal to the IIP, using the expression: "Test $P_{\mathbf{I}} P_{i}$ "-the test will then be performed and if the result is positive (notation: $\mathbf{I}\left(P_{i}\right)=1$ ) $P_{i}$ shall count as fixed; if $\mathbf{I}\left(P_{i}\right)=0$ the premise has failed the test, but may still be defended in the second way: (2) a defense of $P_{i}$ as a substandpoint by putting forward another elementary argument: "Argument $R_{l}, \ldots, R_{m} /$ $P_{i}$ ". The link, however, can be defended only by appealing to the intersubjective linking procedure (or test) ILP to see whether the argument has sufficient force of justification. ${ }^{13}$ The formal expression to be used in this case is: "Test ${ }_{\mathbf{L}} P_{1}, \ldots, P_{n} / S$ ". If $\mathbf{L}\left(P_{1}, \ldots, P_{n} / S\right)=1$, the link will be said to have been fixed. If $\mathbf{L}\left(P_{1}, \ldots, P_{n} / S\right)=0$, the link has failed the test and counts as rejected (successfully attacked).

The turns that follow repeat this pattern: When it is A's turn to move she may challenge any element that was put forward by $\mathbf{P}$ in his preceding turn. When it is P's turn, he may try to defend in all admissible ways each element that was challenged by $\mathbf{A}$ in her preceding turn. Thus, in the course of the discussion, the argument structure of the argument by which $\mathbf{P}$ defends his initial standpoint will become more and more complex. ${ }^{14}$

\footnotetext{
${ }^{12}$ Presumably, in the original version, a test is performed immediately upon demand and its outcome is announced before the discussion proceeds. (van Eemeren and Grootendorst 2004, pp. 145-147) and the same may be assumed for $\mathrm{CD}_{1}$. Anyhow, in $\mathrm{CD}_{1}$, the outcomes of tests do not influence the legitimacy of moves in the ongoing dialogue but only the result of the dialogue (who has won).

${ }^{13}$ As we mentioned before, what is here called ILP actually consists of several procedures. Not all of these need always to be applied to get an outcome.

${ }^{14}$ The present ruling is somewhat simpler than a similar one in (Krabbe 2007), because the latter ruling allows discussants to react to actions of the interlocutor that occurred not in but before the directly preceding turn.
} 
If $\mathbf{A}$ in her move forgoes to challenge a certain element she might have challenged and has closed her turn formally, using the expression "YourTurn", I shall say that A has had sufficient opportunity to challenge it. In this way, the question about the gap in the definition of a successfully defended element (Sect. 2.3) has now been settled.

Below I shall write up the rules of $\mathrm{CD}_{1}$ in the style of defining a Hamblin-type system of formal dialectic (Hamblin 1970, Ch. 8). ${ }^{15}$ So let it be supposed that some underlying formal language has been chosen (italicized capitals refer to sentences of that language), and that the test functions I (for testing propositional elements by the IIP) and $\mathbf{L}$ (for testing links by various procedures combined in the ILP) are available.

\section{RULES OF $\mathrm{CD}_{1}$}

\section{LOCUTION RULES}

Locution types for $\mathbf{P}$ : $\quad$ Standpoint $S$; Test $_{\mathbf{I}} P$; Test $_{\mathbf{L}} P_{1}, \ldots, P_{n} / C$;

Argument $P_{1}, \ldots, P_{n} / C$; YourTurn

Locution types for A: Challenge $P$; Challenge $P_{1}, \ldots, P_{n} / C$; YourTurn

\section{STRUCTURAL RULES}

S0 There are two players: $\mathbf{P}$ and $\mathbf{O}$.

S1 a. A discussion consists of turns. Each turn has one player as its speaker.

Consecutive turns have different speakers.

b. Each player may contribute one or more locutions in each of his or her turns, the last locution being "YourTurn" ("YourTurn" ends the turn).

c. No locution may be repeated within the same turn.

d. Except "YourTurn", no locution may repeat a locution that was used in an earlier turn.

S2 P moves first, putting forward "Standpoint $S$; YourTurn". $S$ is called the initial standpoint of the discussion. The locution type "Standpoint $T$ " does not occur elsewhere in the discussion. ${ }^{16}$

S3 A moves second, putting forward "Challenge $S$; YourTurn", where $S$ is the initial standpoint.

\footnotetext{
15 For a brief description of a prototypical Hamblin system ("System H"), see also van Eemeren et al. (2014), Sect. 6.6 Hamblin's Formal Dialectic.

16 That is to say: not merely may "Standpoint $S$ " not be repeated, but also no other standpoints may be introduced in the discussion by using this type of locution.
} 
S4 In his other turns $\mathbf{P}$ may (unless he would repeat himself), for each propositional formula $P$ such that the preceding turn contained "Challenge $P$ ", put forward a locution "Test ${ }_{\mathbf{I}} P{ }^{17}$ and also one or more locutions "Argument $R_{1}, \ldots, R_{n} / P^{\text {"18}}$; further $\mathbf{P}$ may, if the preceding turn contained a locution "Challenge $P_{1}, \ldots, P_{n} / C$ ", put forward a locution "Test ${ }_{\mathbf{L}} P_{1}, \ldots, P_{n} / C$ ". The only other locution available for $\mathbf{P}$ is "YourTurn".

S5 In her other turns A may, if the preceding turn contained "Argument $P_{1}, \ldots, P_{n}$ / $C$ ", put forward the locution "Challenge $P_{1}, \ldots, P_{n} / C$ ", and also (unless she would repeat herself), for each propositional formula $P_{i}(1 \leq \mathrm{i} \leq \mathrm{n})$, the locution "Challenge $P_{i}$ ". The only other locution available for $\mathbf{A}$ is "YourTurn".

\section{RULES OF WINNING AND LOSING}

W1 The game ends as soon as either discussant passes, i.e. utters in his or her turn merely the locution "YourTurn".

W2 $\mathbf{P}$ wins (A loses) if at the end of the game the initial standpoint has been conclusively defended, otherwise $\mathbf{A}$ wins (P loses). ${ }^{19}$

In the dialogue of Table 1, we see how some of these rules operate. To transform it into a natural language example one may use the following key list:

\section{KEY LIST}

$B$ : We are our brains.

$J$ : Whoever has published more than 400 papers in SCI journals within a field is an expert in that field.

$F$ : The statement that we are our brains belongs to the field of neurobiology.

$P$ : $\quad$ Professor $\mathrm{S}$ has published more than 400 papers in SCI journals within the field of neurobiology.

$C$ : Professor $\mathrm{S}$ claims that we are our brains.

$E$ : Professor $\mathrm{S}$ is an expert in the field of neurobiology.

\footnotetext{
17 As announced, it is not excluded that $\mathbf{P}$ uses this locution type as his second turn $(P$ being the initial standpoint) where $\mathbf{P}$, according to the original version, actually should present an argument rather than demand a test (cf. van Eemeren and Grootendorst 2004, Rule 6c, p. 144).

18 To prevent turns from running on indefinitely, further ruling could be installed putting a limit on the number of different arguments that may be introduced to support one and the same standpoint.

19 In that case $\underline{\mathbf{A}} \underline{\text { has }}$ successfully and conclusively attacked the initial standpoint in the following sense: (1) the initial standpoint failed the identification test (if applied) and (2) any elementary argument that $\mathbf{P}$ put forward in defense of it contains some challenged element (premise or link) that was not successfully defended. That a challenged element was not successfully defended means that it failed any test that was applied to it and was not successfully defended by argument either. See Krabbe 2007. The winning and losing here refers at first only to the argumentation stage, the concluding stage has still to follow.
} 
Table 1 A dialogue in $\mathrm{CD}_{1}$

\begin{tabular}{|c|c|c|c|}
\hline \multicolumn{3}{|c|}{ Speaker's turns } & \multirow[t]{2}{*}{ Results of tests } \\
\hline 1 & P: & Standpoint $B$; YourTurn & \\
\hline 2 & A: & Challenge $B$; YourTurn & \\
\hline 3 & P: & Argument $C, E, F / B ;$ YourTurn & \\
\hline 4 & A: & $\begin{array}{l}\text { Challenge } C \text {; Challenge } E \text {; } \\
\text { Challenge } F \text {; Challenge } C, E, F / B \text {; YourTurn }\end{array}$ & \\
\hline 5 & P: & Test $_{\mathbf{L}} C, E, F / B$; Test $C$; Argument $J, P / E$; Test $F$; YourTurn & $\begin{array}{l}\mathbf{I}(C)=1 \mathbf{I}(F)=0 \\
\mathbf{L}(C, E, F / B)=1\end{array}$ \\
\hline 6 & A: & Challenge $P$; YourTurn & \\
\hline 7 & P: & Test $_{\mathbf{I}} P ;$ YourTurn & $\mathbf{I}(P)=1$ \\
\hline 8 & A: & YourTurn & \\
\hline
\end{tabular}

In the example of Table $1 \mathbf{A}$ wins (and $\mathbf{P}$ loses), because $\mathbf{I}(F)=0$. To check this, one has to apply the definition of "successfully defended" (Sect. 2.3) to see which elements are, at the completion of the discussion, successfully defended and whether the initial standpoint $(B)$ is among them (and, therefore, conclusively defended). First consider $F$. $F$ has been tested, but failed the test, so that $F$ is not fixed (i.e. the basic clause does not apply). Nor has $F$ been defended by argument (the inductive clause does not apply); therefore $F$ is, at the end of the discussion, not a successfully defended element. Now, consider the initial standpoint: $B$ has not been tested, and is therefore not fixed (the basic clause does not apply). $B$ has been defended by just one argument $(C, E, F / B)$ but one of the premises of this argument $(F)$ was attacked but has not been successfully defended (the inductive clause does not apply). Therefore $B$ has, at the end of the discussion, not been successfully defended either and counts as not conclusively defended (but as conclusively attacked).

One may notice that A's challenge of $P$ in turn 6 was superfluous for this result, but that does not mean that this move is illegitimate according to the rules of $\mathrm{CD}_{1}$.

Table 2 A circular dialogue in $\mathrm{CD}_{1}$

\begin{tabular}{|c|c|c|c|}
\hline \multicolumn{3}{|c|}{ Speaker's turns } & \multirow[t]{2}{*}{ Results of tests } \\
\hline 1 & P: & Standpoint $S$; YourTurn & \\
\hline 2 & A: & Challenge $S$; YourTurn & \\
\hline 3 & P: & Test $_{\mathbf{I}} S$; Argument $T / S$; YourTurn & $\mathbf{I}(S)=0$ \\
\hline 4 & A: & Challenge $T$; Challenge $T / S$; YourTurn & \\
\hline 5 & P: & Test $_{\mathbf{I}} T$; Test $_{\mathbf{L}} T / S$; Argument $S / T$; YourTurn & $\begin{array}{l}\mathbf{I}(T)=0 \\
\mathbf{L}(T / \mathbf{S})=1\end{array}$ \\
\hline 6 & A: & Challenge $S / T$; YourTurn & \\
\hline 7 & P: & Test $_{\mathbf{L}} S / T$; YourTurn & $\mathbf{L}(S / T)=1$ \\
\hline 8 & A: & YourTurn & \\
\hline
\end{tabular}


Whereas the initial standpoint is not conclusively defended in this discussion, sub-standpoint $E$ is. Notice that in the argument $J, P / E$ the premise $P$ is fixed and therefore successfully defended by the basic clause. Premise $J$ and the link of this argument were not attacked, whereas in the end $\mathbf{A}$ has had sufficient opportunity to do so (in turn 6), as in fact $\mathbf{A}$ always has in $\mathrm{CD}_{1}$. Therefore $E$ counts as sufficiently and conclusively defended at the end of the discussion.

\section{Application to Circular Argumentation}

Notice that neither the original version nor the system $\mathrm{CD}_{1}$ excludes circular argumentation Consider, for instance, the $\mathrm{CD}_{1}$-dialogue in Table 2.

In this $\mathrm{CD}_{1}$-dialogue $\mathbf{P}$ defends $S$ by means of $T$ and $T$ by means of $S$. Neither $S$ nor $T$, however, has in the end been successfully defended in this way. In $\mathrm{CD}_{1}$ a standpoint cannot be successfully defended by means of just a circular argument because, to say it briefly, a successful defense must be grounded in fixed or definitively unattacked elements. It is not excluded, however, that there is a circular argument for $S$ and also a noncircular argument, and that the latter argument successfully defends $S$.

Anyhow, circular arguments are not outlawed in $\mathrm{CD}_{1}$. Such an outlawing stipulation can, however, easily be introduced. In order to do so I first define a relation of support among propositions.

Let $\mathrm{X}$ be a set of elementary arguments. If $P_{1}, \ldots, P_{n} / C \in \mathrm{X}$ we say that $P_{i}$, in $\mathrm{X}$, directly supports $C(1 \leq \mathrm{i} \leq \mathrm{n})$. The support relation over $\mathrm{X}$ may then be defined as follows:

(a) If $Q$, in $\mathrm{X}$, directly supports $C$ then $Q$, in $\mathrm{X}$, supports $C$.

(b) If $P_{1}, \ldots, P_{n} / C \in \mathrm{X}$ and there is an $\mathrm{i}(1 \leq \mathrm{i} \leq \mathrm{n})$ such that $Q$, in $\mathrm{X}$, supports $P_{i}$ then $Q$, in $\mathrm{X}$, supports $C$.

(c) Support in $\mathrm{X}$ occurs exclusively on the basis of clauses a) and b).

The ban on circular argumentation can now be formulated as follows:

Let $\mathrm{X}$ be the set of arguments that, at a certain point, have been put forward by the Protagonist. The move "Argument $P_{1}, \ldots, P_{n} / C$ " is forbidden for the Protagonist if in the set $\mathrm{X}$, which is obtained by adding $P_{1}, \ldots, P_{n} / C$ to $\mathrm{X}$, one of the $P_{i}$ $(1 \leq \mathrm{i} \leq \mathrm{n})$ supports itself.

\section{Concluding Observations}

In this paper it has been shown that much of the rulings for critical discussion can be formalized. The constructed formalized version of rules for the argumentation stage of critical discussion links up closely with the original version but, as we saw in Sect. 2.7, there are also differences. Some differences, such as the omission of 
retractions or the different stipulations for banning repetitions, concern technical details or simplifications. I here summarize just the more conspicuous differences:

(1) The original version starts out from speech acts, the formalized version from elementary moves (locutions). Speech acts form a deeper layer from which the meaning of elementary moves can be understood, but they are themselves not comprised in the formalization (Sect. 2.1).

(2) In the original version the Protagonist can (officially) defend himself only by means of argumentation (Rule 6c), whereas in the formalized version he can also do so by demanding that a certain test will be performed (Sect. 2.1).

(3) If in the original version the Antagonist attacks the propositional content of an argument, she attacks this content as a whole, whereas in the formalized version an attack at the propositional content must always be directed at a specific premise (Sect. 2.2).

(4) The original version must probably be understood to admit no more than one elementary move in each turn, whereas the formalized version admits a series of elementary moves in each turn (Sect. 2.6).

Yet, with the formal version, I have tried to remain in all respects true to the basic ideas behind the original version. I would even say that the similarity between the two versions is close enough to regard a formal dialectical system such as $\mathrm{CD}_{1}$ not only as a specimen of formal dialectic, but also as an ingredient of the theoretical component of pragma-dialectics. Consequently, formal dialectic and pragma-dialectics, though distinct in many respects, may be said to overlap in that there are certain formal constructions that they are both dealing with.

Obviously, the present formalization $\left(\mathrm{CD}_{1}\right)$ does not represent the only possible way to formalize the argumentation stage of critical discussion. Many variations of the original rules may be developed and their consequences can be elaborated and investigated in formalized versions. The formal approach in Sect. 4 to deal with circular argument may serve as an example. Rules can be made more permissive (as in a variant admitting retractions), but also more rigorous (as in a variant that restricts the Protagonist to only one argument in direct defense of one and the same (sub)standpoint). Also one could, for instance, distinguish between two kinds of attack on the justificatory or refutatory force of an argumentation: one directed at the sufficiency of the argumentation and one directed at its relevance, each kind having its own set of possible defense moves that the Protagonist might use (Snoeck Henkemans 2003, pp. 408-409). ${ }^{20}$

One could perhaps develop formal systems that stay closer to the original version than was done in this paper: for instance by maintaining the original restriction of the content of turns to only one elementary move for each turn, or by relaxing the present formal rules in such a way that discussants are allowed to react to other moves than just those that were put forward in the preceding turn.

\footnotetext{
${ }^{20}$ In either case there is different "strategic advice" communicated to the Protagonist (Krabbe and van Laar 2011).
} 
In general, by studying formalized versions one can gain insights about advantages and disadvantages that variants and refinements of the original version may have for the use of the latter as an (informal) normative model of argumentative discussion. Such insights easily escape notice if one restricts oneself to informal considerations.

I hope that the observations in this paper have shown that pragma-dialectical theory can in various ways profit from investigations that use formalization and that they will stimulate further research in the directions sketched above.

Acknowledgments Earlier versions of this paper were presented at conferences in Leiden (December 2011) and Lille (March 2012). The first presentation was published in Dutch (Krabbe 2013b). The formalization of critical discussion was also discussed in (Krabbe 2013a), which paper had been presented at conferences in Groningen (November 2011) and Vienna (September 2012). I want to thank the audiences of these conferences as well as two anonymous referees of the Dutch version and two anonymous referees of the present version.

Open Access This article is distributed under the terms of the Creative Commons Attribution 4.0 International License (http://creativecommons.org/licenses/by/4.0/), which permits unrestricted use, distribution, and reproduction in any medium, provided you give appropriate credit to the original author(s) and the source, provide a link to the Creative Commons license, and indicate if changes were made.

\section{Appendix: Rules for the Argumentation Stage of Critical Discussion}

\section{Quoted From van Eemeren and Grootendorst (2004), Chapter 6}

\section{Rule 6}

a. The protagonist may always defend the standpoint that he adopts in the initial difference of opinion or in a sub-difference of opinion by performing a complex speech act of argumentation, which then counts as a provisional defense of this standpoint.

b. The antagonist may always attack a standpoint by calling into question the propositional content or the justificatory or refutatory force of the argumentation.

c. The protagonist and the antagonist may not defend or attack standpoints in any other way. (p. 144)

\section{Rule 7}

a. The protagonist has successfully defended the propositional content of a complex speech act of argumentation against an attack by the antagonist if the application of the intersubjective identification procedure yields a positive result or if the propositional content is in second instance accepted by both 
parties as a result of a sub-discussion in which the protagonist has successfully defended a positive sub-standpoint with regard to this propositional content.

b. The antagonist has successfully attacked the propositional content of the complex speech act of argumentation if the application of the intersubjective identification procedure yields a negative result and the protagonist has not successfully defended a positive sub-standpoint with regard to this propositional content in a sub-discussion. (pp. 147-148)

\section{Rule 8}

a. The protagonist has successfully defended a complex speech act of argumentation against an attack by the antagonist with regard to its force of justification or refutation if the application of the intersubjective inference procedure or (after application of the intersubjective explicitization procedure) the application of the intersubjective testing procedure yields a positive result.

b. The antagonist has successfully attacked the force of justification or refutation of the argumentation if the application of the intersubjective inference procedure or (after application of the intersubjective explicitization procedure) the application of the intersubjective testing procedure yields a negative result. (p. 150)

\section{Rule 9}

a. The protagonist has conclusively defended an initial standpoint or substandpoint by means of a complex speech act of argumentation if he has successfully defended both the propositional content called into question by the antagonist and its force of justification or refutation called into question by the antagonist.

b. The antagonist has conclusively attacked the standpoint of the protagonist if he has successfully attacked either the propositional content or the force of justification or refutation of the complex speech act of argumentation. (p. 151)

\section{Rule 10}

The antagonist retains throughout the entire discussion the right to call into question both the propositional content and the force of justification or refutation of every complex speech act of argumentation of the protagonist that the latter has not yet successfully defended. (p. 152)

\section{Rule 11}

The protagonist retains throughout the entire discussion the right to defend both the propositional content and the force of justification or refutation of every complex 
speech act of argumentation that he has performed and not yet successfully defended against every attack by the antagonist. (p. 152)

\section{Rule 12}

The protagonist retains throughout the entire discussion the right to retract any complex speech act of argumentation that he has performed, and thereby to remove the obligation to defend it. (p. 153)

\section{Rule 13}

a. The protagonist and the antagonist may perform the same speech act or the same complex speech act with the same role in the discussion only once.

b. The protagonist and the antagonist must in turn make a move of (complex) speech acts with a particular role in the discussion.

c. The protagonist and the antagonist may not perform more than one move of (complex) speech acts at one time. (p. 154)

\section{References}

Hamblin, C.L. 1970. Fallacies. London: Methuen.

Kleene, Stephen Cole. 1967. Introduction to metamathematics. Fifth reprint. Amsterdam: North-Holland. First ed. 1952.

Krabbe, Erik C. W. 2007. Predicaments of the concluding stage. In Dissensus and the search for common ground, eds. Hans V. Hansen, Christopher W. Tindale, J. Anthony Blair, Ralph H, Johnson, and David M. Godden. CD-ROM. Windsor, ON: OSSA. Reprinted in Dialogues, logics and other strange things: Essays in honour of Shahid Rahman, eds. Cédric Dégremont, Laurent Keiff, and Helge Rückert, pp. 249-261. London: College Publications.

Krabbe, Erik C. W. 2013a. Topical roots of formal dialectic. Argumentation 27(1): 71-87.

Krabbe, Erik C. W. 2013b. De formalisering van kritische discussie [The formalization of critical discussion]. In Studies in taalbeheersing 4 [Studies in speech communication 4], eds. Ronny Boogaart and Henrike Jansen, pp. 233-243.

Krabbe, Erik C. W. and Jan Albert van Laar. 2011. The ways of criticism. Argumentation 25(2): 199-227.

Secades, Alejandro. 2015. A computational model of pragma-dialectics as a tool for its analysis and appraisal. Informal Logic 35(3): 342-377.

Snoeck Henkemans, A.Francisca. 2003. Complex argumentation in a critical discussion. Argumentation 17(4): 405-419.

van Eemeren, Frans H., and Rob Grootendorst. 1984. Speech acts in argumentative discussions: A theoretical model for the analysis of discussions directed towards solving conflicts of opinion. Dordrecht: Foris.

van Eemeren, Frans H., and Rob Grootendorst. 1992. Argumentation, communication, and fallacies: A pragma-dialectical perspective. Hillsdale, $\mathrm{NJ}$ : Erlbaum.

van Eemeren, Frans H., and Rob Grootendorst. 2004. A systematic theory of argumentation: The pragmadialectical approach. Cambridge: Cambridge University Press.

van Eemeren, Frans H., Erik C.W. Krabbe, Bart Garssen, A.Francisca Snoeck Henkemans, Bart Verheij, and Jean H.M. Wagemans. 2014. Handbook of argumentation theory. Dordrecht: Springer.

Visser, Jacky. 2013. A formal account of complex argumentation in a critical discussion. In Virtues of argumentation: Proceedings of the 10th International Conference of the Ontario Society for the 
Study of Argumentation (OSSA), 22-26 May 2013, eds. Dima Mohammed and Marcin Lewinski, pp. 1-14. Windsor, ON: OSSA.

Visser, Jacky. 2015a. A formal perspective on the pragma-dialectical discussion model. In Proceedings of the 8th International Conference of the International Society for the Study of Argumentation (University of Amsterdam, July 1-4, 2014), eds. Bart Garssen, David Godden, Gordon Mitchell and A. Francisca Snoeck Henkemans, pp. 1471-1482. Amsterdam: Sic Sat.

Visser, Jacky. 2015b. Het formaliseren van kritische discussie ter voorbereiding op geautomatiseerde argumentatieanalyse [Formalizing critical discussion in preparation for automated analysis of argumentation]. Tijdschrift voor taalbeheersing [Journal for Speech Communication] 37(3): 321-349.

Visser, Jacky, Floris Bex, Chris Reed, and Bart Garssen. 2011. Correspondence between the pragmadialectical discussion model and the argument interchange format. Studies in Logic, Grammar and Rhetoric 23(36): 189-224. 